\title{
rommhalina
}

(8)

\section{Gil Vicente em Itália}
Autor(es):
Fadda, Sebastiana
Publicado por: Imprensa da Universidade de Coimbra
URL persistente: URI:http://hdl.handle.net/10316.2/47476
DOI: DOl:https://doi.org/10.14195/978-989-26-1548-6_14

Accessed : $\quad$ 26-Apr-2023 12:40:36

A navegação consulta e descarregamento dos títulos inseridos nas Bibliotecas Digitais UC Digitalis, UC Pombalina e UC Impactum, pressupõem a aceitação plena e sem reservas dos Termos e Condições de Uso destas Bibliotecas Digitais, disponíveis em https://digitalis.uc.pt/pt-pt/termos.

Conforme exposto nos referidos Termos e Condições de Uso, o descarregamento de títulos de acesso restrito requer uma licença válida de autorização devendo o utilizador aceder ao(s) documento(s) a partir de um endereço de IP da instituição detentora da supramencionada licença.

Ao utilizador é apenas permitido o descarregamento para uso pessoal, pelo que o emprego do(s) título(s) descarregado(s) para outro fim, designadamente comercial, carece de autorização do respetivo autor ou editor da obra.

Na medida em que todas as obras da UC Digitalis se encontram protegidas pelo Código do Direito de Autor e Direitos Conexos e demais legislação aplicável, toda a cópia, parcial ou total, deste documento, nos casos em que é legalmente admitida, deverá conter ou fazer-se acompanhar por este aviso. 

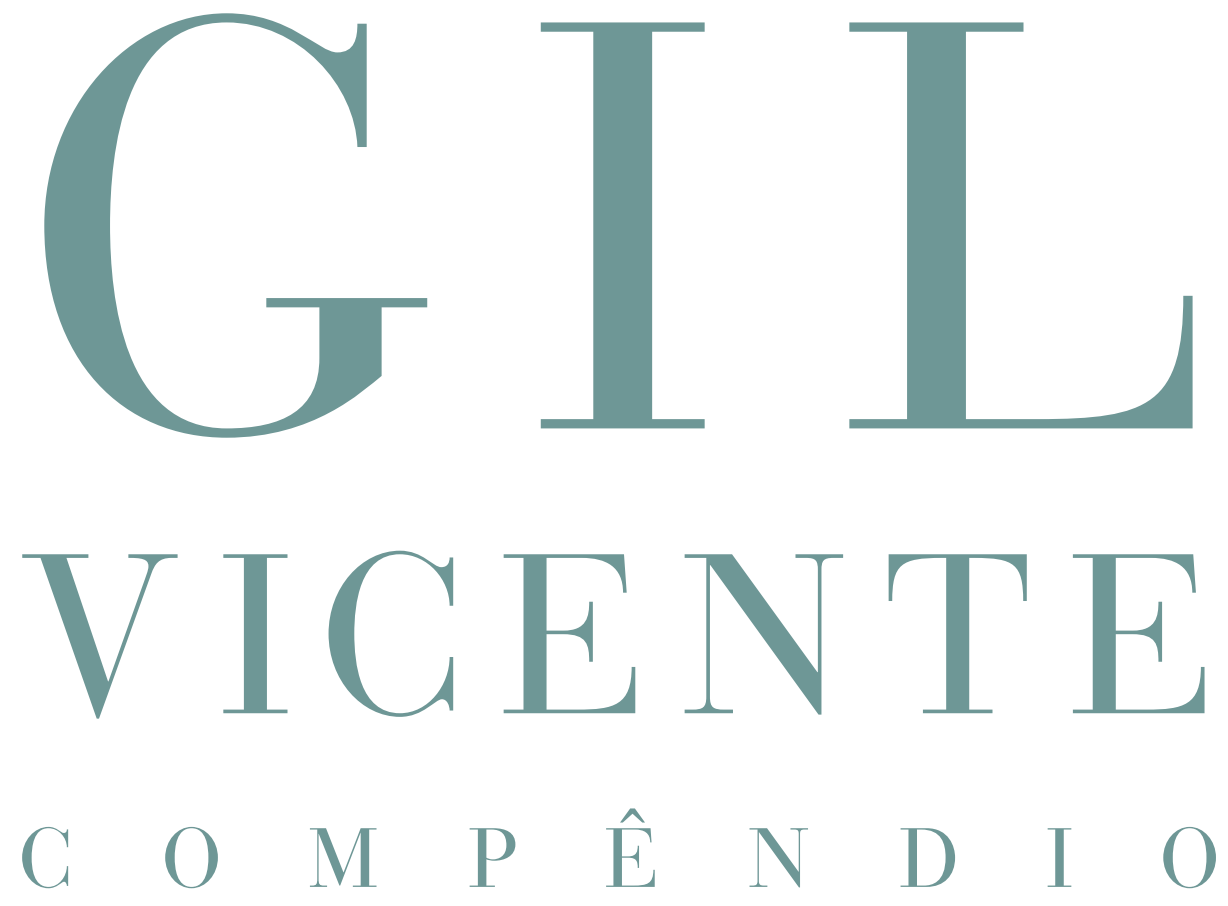

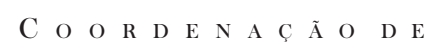

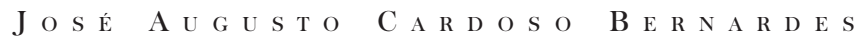

E J O S É C A M Õ E S

CoimbraCompanions

IVPRENSA DA UNIVERSIDADE DE COIMBRA

COIMBRA UNIVERSITY PRESS

IMPRENSA NACIONAL 


\section{XIV}

\section{Gil Vicente em Itália}

Sebastiana Fadda

Centro de Estudos de Teatro

UNIVERSIDADE DE LISBOA 
(Página deixada propositadamente em branco) 


\section{Premissa: Vicente espanhol}

Uma série relativamente recente de estudos críticos e ensaísticos vem tentando preencher a longa ausência de contribuições italianas na bibliografia vicentina. Que causas concorreram para este silêncio? E como explicar o facto de o Frei Luís de Sousa (1843), de Almeida Garrett, ter conhecido uma tradução contemporânea, Frà Luigi di Sousa (1852), por Giovenale Vegezzi-Ruscalla, e a provável primeira tradução de uma obra de Gil Vicente - La Sibilla Cassandra, traduzida pelo académico e hispanista Carlo Bo (in Vittorini, 1941) - ter esperado mais de quatro séculos, incluída num volume com o título emblemático de Teatro spagnolo: Raccolta di drammi e commedie dalle origini ai nostri giorni?

É um facto, no que diz respeito a este último caso, que os originais em castelhano se prestavam ao equívoco, e que o poliglotismo do autor tem legitimado outros episódios de inserção da sua obra em estudos e antologias sobre a dramaturgia hispânica, como aconteceu, por exemplo e limitando a informação à atividade editorial italiana, com a coletânea de peças escolhidas por outro hispanista, Giovanni Maria Bertini, Teatro spagnolo del primo Rinascimento: Juan del Encina, Gil Vicente, Bartolomé de Torres Naharro (s. d. [1945]), onde as peças surgem todas em língua original, contando-se entre elas o Auto de la Sibila Casandra e a Comedia del viudo, sendo esta última um «bordado gracioso e ligeiro, semelhante nalgumas partes ao 'Dom Duardos', tecido pela festiva habilidade de Gil Vicente» 
(Bertini, 1945: 12 [tradução minha]). Tratava-se, por parte de Bertini, duma opção reincidente, uma vez que tinha dado à estampa, pouco tempo antes, aquela mencionada porque já dele familiar Tragicomedia de Dom Duardos (1945), também em castelhano e em volume isolado, que completara com introdução e informação bibliográfica.

Não foi só o teatro que se tornou objeto de atenção por parte de literatos e académicos, mas também a lírica, constituída por um vasto corpus de composições enxertadas na construção dramática, mas cuja estrutura e / ou estilo podem ganhar plena autonomia e estatuto poético. De facto, noutra antologia deste período, organizada pelo germanista Vincenzo Errante em colaboração com o seu aluno Emilio Mariano, intitulada Orfeo. Il tesoro della lirica universale interpretato in versi italiani (1949), transcrevem-se alguns poemas em castelhano agrupados nesta secção linguística e sem indicação das fontes — «La ragazza dagli occhi belli» "Los amores de la niña / que tan lindos ojos ha", do Auto da Lusitânia] / "Canzonetta montanina" [Por dó pasaré la sierra», do Triunfo do Inverno] / "È leggiadra la fanciulla» ["Muy graciosa es la doncella", do Auto da Sibila Cassandra] — podendo-se ler na breve ficha dedicada ao autor: "Escreveu-se que o mais belo poema em língua espanhola (É leggiadra la fanciulla, v. p. 375) se deve a um português.» (Errante/Mariano, 1949: 1744 [t. m.].) Sibila Cassandra é um auto que também Stephen Reckert considera "constelado de alguns dos mais deliciosos poemas breves jamais escritos em língua castelhana” (Reckert, 1983: 22-23), partilhando assim aquela afirmação, que se deve, com toda a probabilidade, a Dâmaso Alonso, dedicado investigador na década de 40 da poesia medieval e vicentina, recordado para reforçar a convicção de que Muy graciosa es la doncella é "la más simplemente bella [poesia] de la lengua castellana" (Alonso apud ibid.: 151). Em contrapartida, no coevo Teatro religioso del Medioevo fuori d'Italia (1949), coletânea de textos do VII ao XV século organizada por outro destacado filólogo desse tempo, Gianfranco Contini, que traduziu em prosa a Trilogia delle barche atribuída ao dramaturgo "fundador do teatro ibérico", e não apenas português, pela mesma editora que poucos anos antes o deu a lume no Teatro spagnolo...

No entanto, é certo que, no que diz respeito à difusão do nome e da obra de Garrett, para além das qualidades literárias, terá contribuído o 
facto de os seus impulsos políticos e dramáticos terem vibrado em uníssono com os de outros literatos liberais internacionais com os quais aliás tinha contactos, como por exemplo o diplomata brasileiro de ascendência luso-alemã Francisco Adolfo de Varnhagen, que mediou a tradução para alemão da obra-prima garrettiana e, com toda a probabilidade, também a italiana, pois é a ele que "o tradutor agradecido e afeiçoado dedica» o seu trabalho (Vegezzi-Ruscalla, in Garrett, 1852: 3 [t. m.]). No ideário liberal reconheciam-se, portanto, os dos irredentistas italianos que ansiavam pelo Risorgimento, cujo entusiasmo em palco era atiçado pelo teatro neoclássico de Vittorio Alfieri e pelo romântico de Alessandro Manzoni.

Rápidas ilações talvez expliquem algumas das razões do temporário ocaso da fama, circulação e representação da obra de Vicente na sua própria pátria.

Se, numa primeira fase e logo a seguir ao falecimento do autor, a hostilidade da Igreja e da Inquisição refreava a divulgação vicentina, a perda da independência e o consequente domínio filipino projetavam a identidade nacional na funda indolência condensada na definição lapidar de Camões, que a denunciou no canto x dos seus Lusíadas como sendo uma «apagada e vil tristeza" (1972: 283). Paralelamente, o gosto pelas farsas rústicas e populares do século XVI viria a ser suplantado pela redescoberta, por parte da literatura erudita, dos universos formais e temáticos clássicos. Pelo surto e êxito de dramaturgias poderosas - como as de Shakespeare, do Siglo de Oro, de Molière e dos tragediógrafos franceses — , pela posterior afirmação da filosofia iluminista que preparava a ascensão da burguesia, pelo favor por esta concedido ao melodrama, às tragédias e às comédias de importação, pela continuada atuação repressiva da censura oficial, Gil Vicente entrava no rol dos autores medievais e populares, banidos até da arqueologia do teatro.

Só mais tarde a recuperação romântica de temas nacionais, quer áulicos quer populares, bebendo nas fontes histórico-literárias da Idade Média, em concomitância com o desenvolvimento dos estudos filológicos, teria repercussões diretas no âmbito teatral. Não é por acaso que às duas edições quinhentistas da obra completa de Gil Vicente se siga uma terceira em 1834, em Hamburgo: a Alemanha, dos irmãos Schlegel aos nossos dias, passando pelas contribuições vicentinas de Carolina Michaëlis, pode ser considerada o pródigo berço da filologia, e não apenas do Romantismo. Poucos anos 
depois, em 1838, Almeida Garrett procederia à tentativa de restauração de um teatro nacional com Um Auto de Gil Vicente, colocando a ação na época manuelina e enxertando cenas de Cortes de Júpiter. É, aliás, de nítida e premeditada inspiração vicentina a famosa passagem do Frei Luís de Sousa onde, a Telmo, que lhe pergunta "Quem és tu?», o Romeiro responde com aquele "Ninguém», vindo diretamente do Auto Chamado da Lusitânia e da Barca do Inferno, como as próprias peças demonstram e outros autores já assinalaram (Remédios, 1907: LVI-LVII; Braga 1942-1944 [1951], I: XLVI-L).

Sobre a mudança de parâmetros na conceção e produção artístico-literária nesta época, é obrigatório referir as considerações da ilustre filóloga e lusitanista Luciana Stegagno Picchio, que, no seu importante ensaio Ricerche sul teatro portoghese (1969: 65-112), repercorreu a fortuna e declínio do teatro de Gil Vicente entre os séculos XVI-XIX, detendo-se em especial sobre as peculiaridades do saiaguês e das línguas homólogas, mas também evidenciando o destino paralelo de Vicente e Ruzante. Dramaturgos populares nas várias aceções do termo (famosíssimos no seu tempo, aderiram às convenções literárias dos falares rústicos e retrataram os respetivos falantes), esquecidos e a seguir exumados no século XIX: críticos literários e linguistas reconheceram as obras nessas mesmas línguas rústicas (estudadas para a reconstrução histórica dos dialetos) e multilíngues como resultado de opções expressivas e estéticas funcionais, correspondentes a convenções literárias bem precisas, tanto assim que obras teatrais consideradas externas, marginais ou inferiores à norma foram reavaliadas e valorizadas mesmo pela sua alteridade.

\section{DivulgaÇão: Vicente PORTUguêS}

O equívoco acima referido acerca da inscrição de Gil Vicente na dramaturgia hispânica e o limbo (ou purgatório) a que a sua obra foi condenada não são uma novidade. Em 1956, Giuseppe Carlo Rossi, refletindo sobre a atenção prestada ao autor pelos literatos italianos, sublinhava que, se do ponto de vista linguístico era lícito considerá-lo como «o primeiro dos grandes dramaturgos da literatura castelhana» (Rossi, 1956: 14), mesmo assim permanecia um ilustre desconhecido: 
As traduções italianas do teatro de Gil Vicente, até ao passado recente, têm sido totalmente inadequadas à importância do autor, às vezes erroneamente apresentado, mais ou menos explicitamente, por alguns dos poucos que mencionaram o seu nome, até como sendo espanhol.

(Ibid.: 27 [t. m.].)

«Inadequadas» é um eufemismo, se pensarmos que os primeiros versos vicentinos em italiano de que haverá rasto - alguns excertos de Il trionfo dell'inverno - se devem a Guido Battelli, controverso poeta, ensaísta, italianista e lusófilo, divulgador da poesia portuguesa em Itália, professor primeiro de língua e depois de história da literatura italiana na Universidade de Coimbra, cuja estada em Portugal se encontra documentada entre 1928 e janeiro de 1932 (Simões, 2010). Aquele fragmento, curiosamente, foi editado em periódicos portugueses: em 1936 na revista portuense Portucale; em 1965 no mensal lisboeta Ocidente, antecedido por uma homenagem de Aura Montenegro, que recorda Battelli com afeto em ocasião dos dez anos do seu falecimento, ocorrido em 1964. Esta fonte refere a intenção e o desejo que houve por parte do tradutor de editar aqueles versos em Itália, o que talvez não chegou a acontecer. O facto de o excerto - o "Argumento da figura primeira do Triunfo do Inverno» (Vicente 2002a, II: 78-80, vv. 78-149) - estar redigido em espanhol não punha em causa a sua pertença ao património literário português, coincidindo com a nacionalidade do autor.

A primeira tradução integral de que há referência, o acima mencionado La Sibilla Cassandra, é, juntamente com a esmagadora maioria dos outros textos que saíram até hoje, uma raridade para bibliófilos. No entanto, tratando-se de uma edição pioneira, de alguma forma terá desbravado o caminho editorial às que seguiram, pois, ainda que esporádica ou intermitente, a aventura dos tradutores tem prosseguido até aos nossos dias.

Se a produção ensaística é irregular, de início insuficiente e limitada quase exclusivamente a notas ou ensaios breves dos próprios tradutores ${ }^{1}$, o auge da fortuna vicentina em italiano regista-se na década de 50. Enzio di

1 Para indicações bibliográficas até 1956, cf. Rossi 1956: 27-28. Em geral, vejam-se as fontes assinaladas na bibliografia passiva, bem como as introduções e os prefácios que integram as obras traduzidas, indicadas na bibliografia ativa. 
Poppa Vòlture dedicou-se à tarefa monumental de traduzir a obra quase completa, em versos rimados, publicada em dois volumes sob o título genérico Teatro (1953-1954); Giuseppe Carlo Rossi ocupou-se de verter em prosa três autos de devoção ("Auto" della visitazione o Monologo del vaccaro, "Auto" pastorale castigliano e "Auto" della barca dell'inferno) que, juntamente com "Auto" dell'India e Farsa di Inês Pereira, apareceram na antologia Teatro portoghese e brasiliano (1956). Guido Battelli saudou a publicação do Teatro com palavras lisonjeadoras:

Gil Vicente apareceu entre nós com todas as honras que lhe eram devidas. Ele é um grande e verdadeiro poeta que sabe reproduzir a vida com um sentido da realidade, mas elevar-se também aos mais altos idealismos artísticos e religiosos. Alegro-me por este poeta ter sido revelado no nosso meio, e estou certo que terá um grande sucesso. (Battelli apud Montenegro, 1965: 23.)

A convicção estava correta, pois houve várias reimpressões. Se o pioneirismo das incursões pontuais, mas significativas, dos lusitanistas e filólogos já referidos - Carlo Bo, Giovanni Maria Bertini e Gianfranco Contini - quebraram um silêncio injustificável, a edição do Teatro possibilitava um mais que devido resgate e a justa redenção.

Poppa Vòlture assinou um número conspícuo de traduções existentes em versão única. A longa lista inclui Auto de S. Martinho, Auto dos Reis Magos, Auto da Fé, Auto dos Quatro Tempos, Auto da Feira, Breve Sumário da História de Deus, Diálogo sobre a Resurreição, Auto da Cananea, Auto de Mofina Mendes, Auto da Festa, Comédia sobre a Divisa da Cidade de Coimbra, Floresta de Enganos, Exortação da Guerra, Cortes de Júpiter, Tragicomédia de Dom Duardos, Frágua de Amor, Templo de Apolo, Nau de Amores, Tragicomédia Pastoril da Serra da Estrela, Auto das Fadas, Auto da Fama, Farsa das Ciganas, O Clérigo da Beira, Farsa dos Almocreves, Auto Chamado da Lusitânia e Auto dos Físicos. Ficaram excluídas dos dois volumes as obras meudas.

Há peças publicadas em mais de uma versão, constando sempre o nome de Poppa Vòlture, que por isso ficará omitido na lista que se segue, assinalando-se somente as ulteriores traduções. Para além das acima mencionadas traduções de Carlo Bo, Gianfranco Contini, Giovanni Maria Bertini e Giuseppe 
Carlo Rossi, há os casos de: Auto da Índia (De Cusatis in Ceccucci/De Cusatis, 1984); Farsa de Inês Pereira (Caratozzolo, 1994, 2000 e 2003); Pranto de Maria Parda (Francavilla e Dallapé, 2002), O Juiz da Beira (Caratozzolo, 2006) e Auto da Barca do Inferno (Tocco, 2014). Na sua antologia, Giuseppe Carlo Rossi recorda uma edição conjunta de Quem Tem Farelos? e Auto da Índia, com comentário e estudo geral sobre o autor, de sua responsabilidade e publicada em Roma em 1953 (cf. Rossi, 1956: 27), mas cujo objeto material não foi possível consultar. Quanto a excertos, para além do citado Trionfo dell'inverno, existem ainda fragmentos selecionados de Auto da Alma e O Velho da Horta (Jannini, 1955), mais alguns punhados de versos da Barca da Glória (Piccolo, 1961 e 1970) e do Purgatório (Piccolo, 1970), semeados em manuais de história da literatura portuguesa. Vale a pena salientar também o interesse genológico dum excerto da Barca do Inferno em versão de Poppa Vòlture (Vicente, 1950), divulgado na revista Estudos Italianos em Portugal três anos antes da publicação integral, demonstrando ser uma das fases intermédias de fixação do texto definitivo. A comparação das duas versões evidencia o caráter provisório e a condição de work in progress inerente ao trabalho de tradução, pois, apesar do breve lapso de tempo que as separa, em várias ocasiões o tradutor interveio com alterações significativas a nível lexical, semântico, sintático e estilístico.

Singular é também a inclusão de Gil Vicente autor de versos em saiaguês e castelhano, com o texto integral do Auto do Vaqueiro ou Auto da Visitação (Stegagno Picchio, 2004: 108-115), considerado como um longo poema, e as duas voltas do Auto da Sibila Cassandra — "Sulla montagna va la donzella» [En la sierra anda la niña»] e "Assai graziosa é la donzella» "Muy graciosa es la doncella»] —, na recente Antologia della poesia portoghese e brasiliana, publicação monumental bilingue, dirigida por Luciana Stegagno Picchio (ibid.: 106-107) e de distribuição capilar no território italiano, assegurada por um grande grupo editorial e posta à venda com o diário Repubblica. Nesta edição, o objetivo da divulgação é claramente a preocupação principal, pelo que se reivindica a liberdade filológica de se subverter a formatação do original, apresentando-se os primeiros dois versos da segunda volta encorpados na primeira, justificando-se esta presença pela nacionalidade do autor e não pelas línguas utilizadas, considerando-se 
mais uma vez esbatidas as fronteiras entre os géneros literários. A Visitação, traduzida por Ugo Serani, sucede, na sequência das páginas, às ditas voltas, traduzidas por Luciana Stegagno Picchio, numa lógica em crescendo que talvez tenha dado prioridade à extensão dos textos e não à sua cronologia. Reiterando a legitimidade das opções subjacentes ao plano e à estrutura da antologia, decerto por razões análogas nela teve espaço um trecho da tragédia A Castro de António Ferreira, privilegiando-se os elementos líricos em detrimento dos dramáticos. Mesmo tendo havido reações polémicas da crítica especializada (Simões, 2005: 242), e apesar de as soluções adotadas se prestarem à contestação, como toda e qualquer publicação, é uma edição de alcance de públicos e leitores notável e talvez sem precedentes no âmbito das letras lusófonas.

Do Auto da Índia houve também uma adaptação operática, musicada pelo compositor Ruy Coelho, com libreto de Gino Saviotti, que a encenou para o Teatro Nacional de S. Carlos, onde foi estreada a 5 de abril de 1962 em versão italiana; a 14 de dezembro do mesmo ano, no mesmo espaço, a ópera foi cantada no original em português (Saviotti, 1967).

Não faltaram, por fim, no âmbito da produção académica, algumas edições críticas, em língua original, com comentários em italiano, de Pranto de Maria Parda em 1963 por Luciana Stegagno Picchio, Comédia de Rubena em 1965 por Giuseppe Tavani e Comedia del viudo em 1977 por Maria Luisa Tobar.

No que diz respeito à passagem da página à cena, raros são os casos em que se conseguiu aceder a registos, mas nem por isso deixam de ser significativos.

Foi acima referido que os dois volumes de Teatro organizados por Poppa Vòlture privilegiaram a tradução em verso. Contudo, a preocupação editorial não terá sido estranha àquela decisão uma legítima preferência e conceção pessoal da tradução literária, porque este tradutor, quando a finalidade é mais pragmática e o resultado se destina à cena e não ao leitor, abdica dos seus princípios. Nas notas que antecedem as peças O Juiz da Beira e Auto Chamado dos Físicos, Vòlture fornece informações suplementares eloquentes, quer em termos teóricos quer factuais. Escreve sobre a primeira: «Esta farsa [Il giudice della Beira], por nós mesmos oportunamente adaptada e convertida em prosa, foi transmitida pelo Segundo Canal da 
R. A. I. no dia 4 de Janeiro de 1953.» (Poppa Vòlture, in Vicente, 1953-1954 [1957], II: 609, t. m.) Mais à frente na mesma fonte, adaptando a informação, reza sobre a segunda: "Esta farsa [I dottori], por nós mesmos adaptada e convertida em prosa, foi transmitida pelo Segundo Programa da R.A.I. no dia 6 de Julho de 1952. Nessa data Gil Vicente entrava assim pela primeira vez, em Itália, em contacto com o grande público.» (Ibid.: 757 [t. m.].)

Dois dados podem ser retidos das duas citações: $a$ ) o advérbio "oportunamente», omitido na segunda citação, parece indicar que o "Poeta», assim é referido o autor quando não é indicado pelo nome próprio, é estilisticamente inviolável na página, mas os seus versos (pelo menos em italiano e no século xx) vacilariam no palco sem a devida reconversão prosástica; $b$ ) o dramaturgo português, confiando nas palavras alusivas de Poppa Vòlture, estreava-se nos palcos (mesmo que televisivos) italianos, que lhe proporcionavam uma audiência potencial da qual não beneficiou com as edições que antecederam os dois volumes de Teatro.

Posteriormente, breves notícias dão conta de apenas dois espetáculos: a Trilogia das Barcas, na tradução de Gianfranco Contini, foi apresentada em forma de oratória no Palazzo Liviano, sede da Universidade de Pádua e foi promovida pelo ilustre colega filólogo Gianfranco Folena (Veronese, 1964: 7); o Pranto de Maria Parda, na versão inspirada e lúdica de Luciano Dallapè, foi representado no claustro medieval da Universidade de Siena numa encenação de Antonio Tabucchi (Tabucchi, 1997: 33). Refira-se que, já mais próximo dos nossos dias, em 2012, o Auto da Barca do Inferno foi traduzido por jovens estudantes no âmbito dum projeto coordenado por Valeria Tocco, promovido pela cátedra Antero de Quental, criada em 2006 através de um protocolo de cooperação assinado entre o Instituto Camões e a Universidade de Pisa; a peça foi representada em português, filmada e carregada no Youtube e no ITunesU desta universidade e publicada numa edição crítica, bilingue e anotada (Tocco, 2014)².

2 Tivemos conhecimento do livro através da recensão saída nos Estudos Italianos em Portugal (Almeida/Camões, 2016: 198-200) e o objeto não nos chegou em tempo útil para análise mais demorada. No entanto, importa referir que ele revela a clara capacidade de estimular o interesse dos alunos, de os desafiar a reencontrarem Vicente, instigando-lhes o desejo de o apresentar a muito mais especialistas. 
Definiu-se a produção ensaística como sendo bastante parca, no entanto seria injusto silenciar a empenhada dedicação de Giuseppe Carlo Rossi, que foi catedrático da primeira cadeira de Língua e Literatura Portuguesa autorizada em Itália, no Instituto Universitário Oriental de Nápoles. Deve ser recordado não apenas como tradutor mas também como ensaísta e autor, entre outros textos, da primeira Storia della letteratura portoghese (1953) e de outro livro panorâmico, La civiltà portoghese: Profilo storico e storico-letterario (1975), que, escusado seria pontualizar, obviamente se detêm sobre a criação vicentina. A esta Luciana Stegagno Picchio reservou todo o segundo capítulo da sua imprescindível Storia del teatro portoghese (1964), bem como muitos artigos assinalados no livro A Lingua Outra: Uma Fotobiografia de Luciana Stegagno Picchio (2001), organizado por Alessandra Mauro.

Permanecendo em âmbito académico e ensaístico, alguma produção dispersa foi editada por Maria Luisa Tobar, hispanista da Universidade de Messina, especialista do Siglo de Oro, tendo de se realçar, da geração mais nova, outro lusitanista, Ugo Serani, autor duma apurada e penetrante reflexão, de que dá conta no estudo L'immagine allo specchio: Il teatro di corte di Gil Vicente (2000), defendido como tese de doutoramento na Universidade de Roma.

Finalmente, nas marcantes comemorações do V Centenário da Visitação por parte do Centro de Estudos de Teatro da Faculdade de Letras da Universidade de Lisboa, estiveram presentes e deram os seus depoimentos originais Luciana Stegagno Picchio, Giuseppe Tavani, Ugo Serani e Vittorio Caratozzolo, que podem ser consultados em Gil Vicente 500 Anos depois - Actas do Congresso Internacional (Brilhante et al., 2003), autêntica celebração duma dramaturgia capaz de estimular olhares renovados sobre o florescimento cultural daquela época e a fertilidade do autor.

\section{TraduÇão: O CASO DA BARCA DO INFERNO}

É curioso mas entende-se o facto de as personagens do Auto da Barca do Inferno terem sido postas a falar publicamente no idioma de Bembo em várias versões num prazo de apenas seis anos, logo a seguir à Segunda Guerra: por Contini, em prosa, em 1949; por Enzio di Poppa Vòlture, em verso, em 1950 
(em excerto) e em 1953 (integralmente); por Giuseppe Carlo Rossi, em prosa, em 1956. Por um lado, esta «moralidade» é dos autos de devoção, e até talvez de todas as peças em geral, a que mais beneficiou de atenção e êxito junto do público. Por outro lado, com a dissolução do partido fascista italiano foram abertas as fronteiras àquelas literaturas cuja circulação, por patriótica preservação da identidade nacional, estava anteriormente vedada ou era desencorajada pelo regime quando não se enquadrava com o seu ideário ou interesses.

Como os três tradutores esclarecem em oportunos textos que antecedem as suas versões da Barca do Inferno, utilizaram edições portuguesas diferentes, pelo que a uma análise contrastiva revelam-se por vezes compreensíveis variantes nas suas propostas. Num dos casos, a opção de manter a estrutura formal primitiva condiciona, provavelmente mais forte e determinantemente do que nos outros dois, o resultado do ato tradutório. Mas o próprio Poppa Vòlture assim se justifica:

Não queríamos voltar à ociosa questão se será mais proveitoso traduzir em verso ou em prosa. Para nós - convicção absolutamente pessoal e sem nenhuma veleidade de a querer impor ou propor — os poetas deveriam ser traduzidos em verso, pela simples razão que foi em verso que escreveram. (Vòlture, 1957: XLIII, t. m.)

A questão inerente ao dilema central do tradutor - poesia versus prosa - e qual das duas hipóteses irá salvaguardar melhor as características do original na língua de chegada - é mesmo ociosa: não havendo perfeita correspondência semântica, formal e rítmica entre duas línguas dadas, seja qual for a decisão tomada haverá perdas inevitáveis, em proveito porém de novas aquisições. Neste caso concreto, a tradução em verso arriscar-se-ia a penalizar os significados em benefício do ritmo, enquanto a versão em prosa sacrificaria a métrica em benefício da clareza dos enunciados. A esse respeito, a homenagem de Giuseppe Carlo Rossi ao literato avança a pari passo com a perplexidade acerca da melhor estratégia a utilizar:

Cabe a E. di Poppa Vòlture a fadiga de ter dado uma tradução completa, em octossilábicos rimados [em italiano, a forma mais próxima da redondilha maior] 
(e aqui perguntamo-nos se, para preservar, nos limites do possível, a harmoniosa "lírica» leveza do teatro de Gil Vicente, desta vez o verso não seria mais indicado, pelo menos intencionalmente, do que a prosa, para a tradução). (Rossi, 1956: 27.)

Rossi, como Contini, resolveu a dúvida optando por uma prosa ritmada, ou seja, pela devolução dos significados mantendo, quando possível, uma sonoridade cadenciada ou rimas e assonâncias internas.

Para tentar individualizar os critérios que orientaram as opções dos três tradutores, a eficácia das soluções adotadas, as eventuais vantagens e desvantagens das mesmas, difícil é subtrair-se a uma apreciação que evite a prática mais comum de se avaliar a sua idoneidade operativa, tendo-se em conta o grau de equivalência ou de afastamento entre língua de partida e língua de chegada.

A metodologia adotada por Enzio di Poppa Vòlture, conforme a classificação codificada por André Lefevere (apud Bassnett, 2003: 137-138; tb. apud Gentzler, 1998: 106), responderia aos dois critérios seguintes: a) o da tradução métrica, que acompanha o metro do original e assume a responsabilidade de distorcer o sentido e a sintaxe; b) o da tradução em rima, que impõe limites ou reviravoltas no âmbito da devolução dos significados, a risco de o resultado rasar o enfado ou a pedantice.

Neste caso concreto, a distorção do sentido é mínima, pelo facto de as duas línguas envolvidas no processo tradutório pertencerem à mesma cepa, e o artifício da sintaxe, sempre dentro da convenção literária, é intencional e parte do gosto subjetivo do tradutor. Mesmo sendo reduzidos os efeitos negativos principais dos critérios adotados, as frequentes disposições sintáticas latinizantes e as opções lexicais eruditas geram por vezes algumas fragilidades, tanto na caracterização das personagens, devido à tendência para a uniformização dos registos, como na fluência das réplicas, pela inibição da oralidade sob o ponto de vista cénico. A frequência e abundância das notas, aliás, demonstra que estamos perante uma tradução para ser lida, talvez mais "criativa» do que "científica» ou "coloquial», mais preocupada em criar uma linguagem artificial, nos moldes de um improvável italiano do século XVI (época em que não havia Itália nem língua nacional), do que em dirigir-se aos contemporâneos. 
Gianfranco Contini e Giuseppe Carlo Rossi, ainda na base da catalogação sistematizadora de Lefevere (ibidem), ter-se-iam fundamentado em outros princípios: a) o da tradução literal, que privilegia a transferência do significado, mas pode inserir explicações abusivas a preço das qualidades literárias; b) o da tradução em prosa, que evita os desvios semânticos, a risco de suprimir as valências poéticas.

É certo que Contini usa as palavras, e procura a sua etimologia, com um zelo filológico irrepreensível, dando prioridade à economia de meios, mas as suas frases são por vezes quase secas e com ritmo claudicante. Dito por outras palavras, a dele é uma tradução literal, em que as valências poéticas nem sempre conseguem alcançar a altura dos voos primitivos, e cuja maior qualidade é talvez a eficácia do ponto de vista cénico.

Giuseppe Carlo Rossi dedica extrema atenção à musicalidade e, apesar de ter renunciado à métrica, procura não abdicar da poesia, perseguindo um resultado que poderíamos definir coincidente com a prosa poética ou ritmada. Na realidade, trata-se de uma tradução em prosa, em que as explicações não são abusivas mas, mesmo que esporadicamente, podem pecar por prolixidade. Os destinatários ideais são tanto os leitores (e houve, com toda a probabilidade, recetores atentos no meio académico, não apenas entre os seus alunos) como os espectadores (que não chegou a ter, ao que tudo indica).

A criatividade, fundamental na própria fase de interpretação do texto de partida, é imprescindível no trabalho de tradução, mas as doses parecem mudar, conforme o grau de autonomia ou de dependência do original que cada tradutor autoriza a si próprio. A exatidão e abrangência interpretativa, ainda, deriva do (e demonstra o) nível de competência linguística possuído nas duas línguas.

Nos três casos considerados, a criatividade varia, a competência é elevada, o produto final visa a coerência, no sentido de encarar a obra como um todo, e concilia pressupostos, objetivos e metodologia pessoais: Gianfranco Contini, a investigação académica e a prática do palco, tendo como destinatário privilegiado o espectador; Enzio di Poppa Vòlture, o idealismo romântico e a transfiguração criadora, tendo como público-alvo o leitor; Giuseppe Carlo Rossi, a síntese entre romantismo e cientificidade, ambicionando dirigir-se tanto a leitores como a espectadores. Numa recensão aos estudos portugueses em Itália, Roberto Barchiesi evidencia as 
intenções diferentes que animaram os últimos dois em termos de originalidade e fidelidade, chegando a identificar, nas suas traduções do Frei Luís de Sousa de Almeida Garrett - Poppa Vòlture, Il romeo (1957); Rossi, Frà Luigi di Sousa (1956) —, a estratégia domesticadora no primeiro caso, com o domínio da cultura de chegada para se levar o autor ao leitor, e a estratégia distanciadora no segundo, com o domínio da cultura de partida para se levar o autor ao leitor. No entanto, essas fronteiras não parecem tão intransponíveis no caso das traduções vicentinas, a que se reporta a seguinte apreciação crítica:

Di Poppa, mais extravagante, ele próprio poeta e estudioso, preocupado com os valores formais, está constantemente envolvido num trabalho de reformulação e recriação - às vezes feliz, outras vezes até arbitrária — enquanto Rossi está concentrado principalmente na preocupação filológica da integridade e da correspondência textual. Di Poppa [...] esforça-se para agarrar antes de tudo a agilidade do tom poético sem inibições, a fim de alcançar o seu propósito, forçando, por vezes, o conteúdo lógico. Rossi, no entanto, apesar de considerar o problema do verso [...], optou por fim por esta última [a prosa] como sendo a mais apta para manter a tradução fiel ao original. (Barchiesi, 1957: 67-68.)

O facto de nem sempre o resultado corresponder às expectativas dos recetores, às bitolas da crítica ou até mesmo às aspirações dos tradutores, não significa que esse resultado tenha falhado. A procura da lógica subjacente ao processo tradutório, através da análise do texto de chegada, permite reconhecer que não há, nem poderia haver, uma maneira certa de traduzir. Existem, sim, para cada obra e para cada época, tantas interpretações, e respetivos condicionamentos, quantos tradutores se debruçarem nelas. Numa perspetiva humanista, a função principal da tradução é a de preservar, divulgar e transmitir conhecimentos que de outra forma estariam reservados a um público restrito ou ficariam perdidos. O autor poderá assim sobreviver, tal como defendia Benjamin (apud Venuti: 11-12), ou ressuscitar num outro corpo, segundo a metáfora de Hilaire Belloc (apud Bassnett: 185). À pergunta se e como Gil Vicente sobreviveu, ou se houve transubstanciação nas Barcas consideradas, poder-se-á responder que o autor e a 
obra lá foram navegando, em conformidade com o universo conceptual e linguístico dos três tradutores que naquelas águas ousaram aventurar-se.

\section{BibliografiA}

Almeida, Maria João; Camões, José (2016), "Gil Vicente, Auto da barca do inferno. La barca dell'inferno, cura, coordinamento e revisione Valeria Tocco [...]", Estudos Italianos em Portugal, Nova Série, Lisboa, Instituto Italiano de Cultura de Lisboa, n. ${ }^{11}$, pp. 198-200.

[Anónimo] (1954), "Rassegna bibliografica. Gli studi portoghesi in Italia», Estudos Italianos em Portugal, Lisboa, Istituto Italiano di Cultura in Portogallo, n. ${ }^{\circ}$ 13, pp. 95-97 [recensão não assinada, com provável autoria do redator Roberto Barchiesi].

[Anónimo] (1997), "Un'eroina blasfema e disperata, parodia del sacro», Corriere della sera, 26 de junho, p. 27 [artigo de autoria não identificada, encerrado pela sigla «P.Dist.»].

Barchiesi, Roberto (1957), "Studi portoghesi in Italia», Estudos Italianos em Portugal, Lisboa, Istituto Italiano di Cultura in Portogallo, n. ${ }^{\circ} 16$, pp. 66-68.

Bassnett, Susan (2003), Estudos de Tradução: Fundamentos de Uma Disciplina, tradução de Vivina de Campos Figueiredo, revisão de Ana Maria Chaves, Lisboa, Fundação Calouste Gulbenkian, Serviço de Educação e Bolsas.

Bertini, Giovanni Maria (a cura di) (s. d. [1945]), Teatro spagnolo del primo Rinascimento. Juan del Encina, Gil Vicente, Bartolomé de Torres Naharro (premessa, testo e glossario a cura di G.M. Bertini), Venezia, Stamperia Editrice già Zanetti.

Brilhante, Maria João; Camões, José; Silva, Helena Reis; Ribeiro, Cristina Almeida (org.) (2003), Gil Vicente 500 Anos depois - Actas do Congresso Internacional, Lisboa, Imprensa NacionalCasa da Moeda, Estudos e Temas Portugueses, 2 vols.

Camões, Luís de, Os Lusíadas (leitura, prefácio e notas de Álvaro Júlio da Costa Pimpão), Lisboa, Instituto de Alta Cultura, Imprensa Nacional-Casa da Moeda, 1972.

Caratozzolo, Vittorio (2001), "Un testo teatrale "costruito" su un proverbio: la farsa di Inês Pereira di Gil Vicente», in Atti del Convegno Internazionale "Il senno di Bertoldo. Saperi, formule, espressioni dell'identità popolare", Alessandria, Dell'Orso.

— (2002), "Avventure e disavventure di un traduttore di Gil Vicente in Italia", in Polifonia, Lisboa, UNIL, Grupo de Investigação em Línguas Vivas, Faculdade de Letras, Universidade de Lisboa, n. ${ }^{\circ}$ 5, pp. 55-79.

Ceccucci, Piero; De Cusatis, Brunello (1984), Cultura e società nel Portogallo del XVI secolo, Perugia, Università degli Studi di Perugia.

Contini, Gianfranco (a cura di) (1949), Teatro religioso del Medioevo fuori d'Italia, Milano, Bompiani.

Dolci, Guido (1957), "Gil Vicente na língua italiana", separata do Boletim Cultural da Câmara Municipal do Porto, n. ${ }^{\circ} 20$, pp. 292-298.

Errante, Vincenzo; Mariano, Emilio (a cura di) (1949), Orfeo. Il tesoro della lirica universale interpretato in versi italiani, Firenze, Sansoni.

Fadda, Sebastiana (2006), Eco e risonanze. Dramaturgia portuguesa em tradução, tese de doutoramento, Lisboa, Faculdade de Letras da Universidade de Lisboa (texto policopiado).

- (2011), "Gil Vicente nosso contemporâneo, académico e poliglota», in Manuel Calderón; José Camões; José Pedro Sousa (org.), Por s'entender bem a letra. Homenagem a Stephen Reckert, Lisboa, Imprensa Nacional-Casa da Moeda, pp. 675-686. 
Francavilla, Roberto (a cura di) (2002), Gil Vicente. Il Pranto di Maria Parda [com um texto de Antonio Tabucchi e a tradução em verso de Luciano Dallapè], Siena, Protagon.

Garrett, Almeida (1852), Frà Luigi di Sousa, trad. Giovenale Vegezzi-Ruscalla, Torino, Tipografia Speirani e Tortone.

- (1956), Frà Luigi di Sousa, in Giuseppe Carlo Rossi (a cura di), Teatro portoghese e brasiliano, Milano, Teatro di Tutto il Mondo, Thesaurus Litterarum, Nuova Accademia Editrice.

- (1957), Il romeo, in Teatro e narrativa (Un "Auto" di Gil Vicente, Il romeo, La fanciulla dei rosignoli) (introduzione, traduzione e note a cura di Enzio di Poppa Vòlture), Torino, I Grandi Scrittori Stranieri, Unione Tipografico-Editrice Torinese.

Gentzler, Edwin (1998), Teorie della traduzione. Tendenze contemporanee, Torino, UTET.

Jannini, Pasquale Anjel (1955), Pagine di letteratura portoghese, Milano, Nuova Accademia Editrice.

Mauro, Alessandra (org.) (2001), A Lingua Outra: Uma Fotobiografia de Luciana Stegagno Picchio, Lisboa, Instituto Camões.

Mazzoni, Guido (1934), "L'Italia nell' Auto da Fama di Gil Vicente», in Atti della R. Accademia Nazionale dei Lincei, Rendiconti della Classe di Scienze Morali, Storiche e Filologiche, serie VI, vol. IX, fasc. 11-11, Roma.

Montenegro, Aura (1965), "Doutor Guido Battelli, insigne lusófilo. 1. ${ }^{\circ}$ decénio do seu falecimento", Ocidente, vol. LXIX, n. ${ }^{\circ} 327$, julho.

Piccolo, Francesco (1961), Storia della letteratura portoghese, Milano, Nuova Accademia Editrice.

- (1970), La letteratura portoghese, Firenze-Milano, Sansoni-Accademia.

Poppa Vòlture, Enzio di (1952), "Gil Vicente compiuto poeta", estratto da Convivium raccolta nuova, n. ${ }^{\circ}$ 2, Società Editrice Internazionale, Torino-Milano-Genova-Parma-Roma-Catania, pp. 216-232.

- (1953), "Gil Vicente poeta social», O Primeiro de Janeiro, 25 de novembro, p. 3.

- (1967), "Musa lusitana», Estudos Italianos em Portugal, Istituto Italiano di Cultura in Portogallo, Lisboa, n. ${ }^{\circ}$ 29, pp. 177-185.

Quaderni Portohesi (1981) [monografia], Pisa, Giardini, 9-10, Primavera-Autunno.

Reckert, Stephen (1983), Espírito e Letra de Gil Vicente, Lisboa, Imprensa Nacional-Casa da Moeda, Temas Portugueses.

Rossi, Giuseppe Carlo (1953), Storia della letteratura portoghese, Firenze, Sansoni.

- (1955), "Il problema dei testi di Gil Vicente», Filologia Romanza, anno II, fasc. $3 .^{\circ}$, n. $^{\circ} 7$, pp. 314-323.

- (a cura di) (1956), Teatro portoghese e brasiliano, Milano, Nuova Accademia Editrice.

- (1975), La civiltà portoghese, Torino, Mursia.

Saviotti, Gino (1967), "Inês Pereira. Ópera cómica em 3 actos inspirada nas farsas de Gil Vicente», Estudos Italianos em Portugal, Lisboa, Istituto di Cultura Italiana in Portogallo, n. ${ }^{\circ} 28$.

Serani, Ugo (2000), L'immagine allo specchio. Il teatro di corte di Gil Vicente, Roma, Bagatto Libri. Simões, Manuel G. (2005), «Recensões: Poesia straniera, collana a cura di Francesco Stella, Antologia della poesia portoghese e brasiliana direta da Luciana Stegagno Picchion, Estudos Italianos em Portugal, Lisboa, Instituto Italiano de Cultura de Lisboa, nova série, n. ${ }^{\circ}$ 0, pp. 240-244.

- (2010), "Guido Battelli e a poesia portuguesa», Estudos Italianos em Portugal, Lisboa, Instituto Italiano de Cultura de Lisboa, nova série, n. ${ }^{\circ}$, pp. 135-149.

Stathatos, Constantin C. (1980), A Gil Vicente Bibliography: 1940-1975, pref. by Thomas R. Hart, London, Grant \& Cutler.

- (2004), Bartolomé de Torres Naharro: A Bibliography (1517-2003), Kassel, Reichenberger.

Stegagno Picchio, Luciana (1964), Storia del teatro portoghese, Roma, Edizioni dell'Ateneo.

- (1969), História do Teatro Português, Lisboa, Portugália Editora. 
- (1969), Ricerche sul teatro portoghese, Roma, Edizioni dell'Ateneo.

- (dir.) (2004), Antologia della poesia portoghese e brasiliana, Firenze, La Biblioteca di Repubblica. Tabucchi, Antonio (1997), "Il canto della santa bevitrice», Corriere della Sera, 26 di giugno, p. 33. Tobar, Maria Luisa (a cura di) (1983), "Para una protohistoria del entremés. Gil Vicente autor de piezas entremesiles», Nuovi Annali della Facoltà di Magistero dell'Università di Messina, 1, Roma, Editrice Herder.

- (1986), "Toda comedia comienza en dolores. Notas en torno a la comedia de Gil Vicente», Nuovi Annali della Facoltà di Magistero dell'Università di Messina, 4, Roma, Editrice Herder.

- (1990a), "La estrutura de la comedia vicentina", estratto da Messana, Rassegna di Studi Filologici, Linguistici e Storici, nuova serie, 2, Sicania Editore.

- (1990b), "Los príncipes disfrazados en las comedias de Gil Vicente», estratto da Messana, Rassegna di Studi Filologici, Linguistici e Storici, nuova serie, 5, Sicania Editore.

Venuti, Lawrence (ed.) (2000), The Translation Studies Readers, London and New York, Routledge. Veronese, Paolo (1964), "Trilogia delle barche al Liviano di Padova", Il gazzettino, 5 dicembre, p. 7. Vian, Cesco (a cura di) (1969), Antologia della letteratura portoghese e brasiliana, Milano, Fratelli Fabbri Editori.

- (1985), Storia della letteratura spagnola, ispanoamericana, portoghese e brasiliana, Milano, Fratelli Fabbri Editori.

Vicente, Gil (1907), Obras de Gil Vicente, revisão, prefácio e notas por Mendes dos Remédios, Coimbra, França Amado Editor.

- (1936), «Il trionfo dell'inverno» [excerto], tradução de Guido Battelli, in Portucale, Porto, vol. IX, n. ${ }^{\circ} 35$.

- (1942-1944 [1951]), Obras Completas, com prefácio e notas de Marques Braga, Lisboa, Clássicos Sá da Costa Editora, 6 vols.

- (1945), Tragicomedia de Don Duardos, introduzione e informazione bibliografica di Giovanni Maria Bertini, Torino, Chiantore.

- (1950), "La Barca d'Inferno» [excertos, tradução de Enzio di Poppa Vòlture], Estudos Italianos em Portugal, Istituto Italiano di Cultura in Portogallo, Lisboa, n. ${ }^{\text {s }}$ 9-10-11, pp. 59-65.

- (1953-1954 [1957]), Teatro, traduzione, introduzione e note di Enzio di Poppa Vòlture, Firenze, Sansoni, 2 vols., [reimpresso em 1957 e 1963].

- (1963), "Il Pranto de Maria Parda di Gil Vicente», introduzione, testo critico e commento di Luciana Stegagno Picchio, Annali dell'Istituto Universitario Orientale di Napoli, Napoli, Istituto Universitario Orientale, Sezione Romanza, V, 1.

- (1965), Comedia de Rubena, introduzione, testo e note di Giuseppe Tavani, Roma, Edizioni dell'Ateneo.

- (1977), Comedia del viudo, a cura di Maria Luisa Tobar, Messina, Peloritana.

- (1992), Trilogia delle barche, traduzione di Gianfranco Contini, nota al testo di Claudio Ciociola, Torino, Giulio Einaudi Editore.

- (1994), Farsa di Inês Pereira, traduzione e cura di Vittorio Caratozzolo, Parma, Nuova Pratiche Editrice [tb. Trento, Luni, 2000; Roma, Carocci, 2006].

- (2002a), As Obras, direção científica de José Camões, prefácio de Ivo Castro, Lisboa, Imprensa Nacional-Casa da Moeda, Clássicos, 5 vols.

- (2002b), Il Pranto de Maria Parda, lettura critica, introduzione e note di Roberto Francavilla, con una traduzione in rima di Luciano Dallapé e un testo di Antonio Tabucchi, Siena, Protagon Editori Toscani.

- (2006), Il giudice della Beira, traduzione e cura di Vittorio Caratozzolo, Roma, Carocci Editore, Biblioteca Medievale. 


\section{PARTE - TRADUÇÕES}

- (2014), Auto da barca do inferno. La barca dell'inferno, cura, coordinamento e revisione di Valeria Tocco, introduzione, edizione e traduzione dal portoghese di Benedetta Campennì, Alice Catalano, Francesca Giannelli, Chiara Morleo e Rebecca Martignoni, Colle di Val d'Elsa, Vittoria Iguazu Editora.

Vittorini, Elio (a cura di) (1941), Teatro spagnolo. Raccolta di drammi e commedie dalle origini ai nostri giorni, Milano, Bompiani, Pantheon. 